\title{
Deficient retinoid-driven angiogenesis may contribute to failure of adult human lung regeneration in emphysema
}

\author{
John-Poul Ng-Blichfeldt, ${ }^{1}$ Joana Alçada, ${ }^{1,2}$ M Angeles Montero, ${ }^{3}$ Charlotte H Dean, ${ }^{1}$ \\ Uta Griesenbach, ${ }^{4}$ Mark J Griffiths, ${ }^{1,2}$ Matthew Hind ${ }^{1,2}$
}

\begin{abstract}
- Additional material is published online only. To view please visit the journal online (http://dx.doi.org/10.1136/ thoraxjnl-2016-208846).

IInflammation, Repair and Development, National Heart and Lung Institute, Imperial College London, London, UK ${ }^{2}$ Royal Brompton and Harefield NHS Foundation Trust, London, UK

3Department of Histopathology, Royal Brompton and Harefield NHS Foundation Trust, London, UK

${ }^{4}$ Department of Gene Therapy, National Heart and Lung Institute, Imperial College London, London, UK
\end{abstract}

\section{Correspondence to}

Matthew Hind, Royal Brompton and Harefield NHS Foundation Trust, Sydney Street, London SW3 6NP, UK; m.hind@imperial. ac.uk

CHD, UG, MJG and MH contributed equally to this paper

Received 27 April 2016 Revised 8 November 2016 Accepted 21 December 2016 Published Online First 13 January 2017

\section{ABSTRACT}

Background Molecular pathways that regulate alveolar development and adult repair represent potential therapeutic targets for emphysema. Signalling via retinoic acid (RA), derived from vitamin $A$, is required for mammalian alveologenesis, and exogenous RA can induce alveolar regeneration in rodents. Little is known about RA signalling in the human lung and its potential role in lung disease.

Objectives To examine regulation of human alveolar epithelial and endothelial repair by RA, and characterise RA signalling in human emphysema.

Methods The role of RA signalling in alveolar epithelial repair was investigated with a scratch assay using an alveolar cell line (A549) and primary human alveolar type 2 (AT2) cells from resected lung, and the role in angiogenesis using a tube formation assay with human lung microvascular endothelial cells (HLMVEC). Localisation of RA synthetic (RALDH-1) and degrading (cytochrome P450 subfamily 26 A1 (CYP26A1)) enzymes in human lung was determined by immunofluorescence. Regulation of RA pathway components was investigated in emphysematous and control human lung tissue by quantitative real-time PCR and Western analysis.

Results RA stimulated HLMVEC angiogenesis in vitro; this was partially reproduced with a RAR- $\alpha$ agonist. RA induced mRNA expression of vascular endothelial growth factor A (VEGFA) and VEGFR2. RA did not modulate AT2 repair. CYP26A1 protein was identified in human lung microvasculature, whereas RALDH-1 partially colocalised with vimentin-positive fibroblasts. CYP26A1 mRNA and protein were increased in emphysema.

Conclusions RA regulates lung microvascular angiogenesis; the endothelium produces CYP26A1 which is increased in emphysema, possibly leading to reduced RA availability. These data highlight a role for RA in maintenance of the human pulmonary microvascular endothelium.

\section{INTRODUCTION}

The adult mammalian lung has a robust capacity to regenerate following various types of injury; recent evidence suggests this is, at least partially, conserved in man. ${ }^{12}$ Whilst there has been progress in understanding factors that influence lung function decline in COPD, the molecular and cellular biology of human lung repair remains poorly understood. ${ }^{3}$ Molecular pathways that regulate lung development may also be important for lung

\section{Key messages}

What is the key question?

- What is the role of retinoic acid (RA) signalling in adult human alveolar repair?

What is the bottom line?

- Exogenous RA stimulates angiogenesis and induces expression of vascular endothelial growth factor A (VEGFA) and VEGFR2 mRNA in human lung microvascular endothelial cells. The RA catabolic enzyme cytochrome P450 subfamily 26 A1 (CYP26A1) localises to microvascular endothelium in human lung tissue, whereas the RA synthetic enzyme RALDH-1 localises to a distinct population of alveolar cells that includes vimentin-positive stromal cells. Expression of CYP26A1 is increased in emphysematous lung tissue. These data suggest endogenous RA signalling regulates alveolar maintenance in man via the pulmonary microvascular endothelium, and furthermore, dysregulated endothelial RA catabolism may contribute to chronic lung disease.

\section{Why read on?}

- This study for the first time describes how endogenous RA may regulate lung cellular repair processes in man and identifies the pulmonary microvascular endothelium as a therapeutic target for human lung regeneration.

repair in adulthood, ${ }^{4}$ and emerging data implicate the critical developmental factor retinoic acid (RA). $\mathrm{RA}$ is a small lipophilic molecule derived from dietary vitamin A (retinol). Circulating retinol binds to cytoplasmic retinol binding proteins (CRBP-1 or CRBP-2), and is converted by sequential oxidation by alcohol dehydrogenases and retinaldehyde dehydrogenases (RALDH) into biologically active all-trans RA (ATRA). ${ }^{5}$ Cellular retinoic acid binding proteins (CRABP)- 1 and CRABP-2 transport ATRA either to cytochrome P450 subfamily 26 enzymes (CYP26A1, B1 or C1) for degradation, or to cognate type 2 nuclear retinoic acid receptors (RAR- $\alpha$, RAR- $\beta$ and RAR- $\gamma$ ) and 
retinoid X receptors (RXR- $\alpha$, RXR- $\beta$ and RXR- $\gamma$ ). These interactions regulate the activity of a wide assortment of genes. ${ }^{6}$

RA signalling has well defined roles in development and regeneration of various organs across species. ${ }^{7}$ In the lung, RA signalling regulates the outgrowth of nascent lung buds from foregut endoderm in the earliest stages of development, ${ }^{8}$ and is required post-natally in mice for alveologenesis, as demonstrated by alveolar defects resulting from targeted RAR disruptions. ${ }^{9-11}$ In adult rodents, endogenous RA signalling is required for alveolar maintenance; vitamin A deficiency in adult rats caused alveolar destruction and loss of gas-exchanging surface area, hallmarks of emphysema. ${ }^{12}$ Exogenous RA administration modulated alveolar regeneration following pneumonectomy in adult rodents and dogs, ${ }^{13}{ }^{14}$ and remarkably, both RA and RAR agonists induced alveolar regeneration in adult rodent models of emphysema. ${ }^{15-18}$

Exogenous retinoids regulate lung function in man; maternal retinol supplementation in areas of endemic vitamin A deficiency improved childhood lung function. ${ }^{19}$ Recent data have identified a novel RA pathway gene as being important in determining adult FVC. ${ }^{20}$ In adults, serum retinol correlated with lung function in healthy subjects, ${ }^{21}$ and in patients with COPD, reduced serum retinol preceding decline in lung function. ${ }^{22}$ The cellular and molecular biology underlying these observations is not currently understood. RA signalling defects have been described in fibroblasts isolated from human emphysematous lung tissue. ${ }^{23}$ However, very little is known about the role of endogenous RA signalling in resident cells of the alveolus and how this might contribute to alveolar homeostasis.

In this paper, we characterise RA signalling in distal human lung and examine the role of RA in primary human alveolar epithelial and endothelial cell processes likely to be important in lung repair or regeneration. We demonstrate pathway components mediating RA synthesis and breakdown are localised to specific cell populations and identify increased capacity for RA catabolism in emphysematous lung.

\section{METHODS}

\section{Tissue samples}

All human lung tissue samples were obtained from the Biobank of the Respiratory Biomedical Research Unit (BRU), Royal Brompton and Harefield NHS Foundation Trust (ethics reference number 10/H0504/9). Control lung was obtained from patients undergoing surgical resection for suspected lung tumours and comprised histologically normal parenchymal tissue not directly involved in the excised lung cancer. Emphysematous lung comprised parenchymal tissue obtained from patients undergoing lung volume reduction surgery for severe radiological emphysema. Lung samples were confirmed as histologically normal (control) or emphysematous according to tissue sections derived from regions immediately adjacent to frozen samples used in this study by an independent histopathologist (see online supplementary material). Patient demographics were obtained from anonymised clinical records with full consent (table 1). Control and emphysema groups were matched for age and sex. To determine the overlap between pathological emphysema and the physiology of the control group, which included patients with non-obstructed lung disease and patients with COPD, statistical tests were performed on lung function parameters between groups. Patients with emphysema exhibited a trend towards higher pack years, and lower FVC $(p=0.07)$ than control patients. Patients with emphysema had significantly lower total lung capacity $(\mathrm{p}=0.04), \mathrm{FEV}_{1}, \%$ predicted $(\mathrm{p}=0.0002), \mathrm{FEV}_{1} / \mathrm{FVC}$ ratio
Table 1 Patient demographics and pulmonary function values associated with samples used in this study

\begin{tabular}{lll}
\hline & Control & Emphysema \\
\hline Age, year & $64.7 \pm 3.2$ & $56.2 \pm 2.9$ \\
Sex ratio, M/F & $9 / 5$ & $9 / 6$ \\
Pack-years & $14.5(0-40)$ & $35(19-53)$ \\
TLC, L & $5.8(5.6-7.4)$ & $8.5(6.1-9.2)^{*}$ \\
FEV $_{1}, \%$ pred & $88(68-99)$ & $29(25-40)^{* * *}$ \\
FVC, L $^{*}$ & $3.2(3.0-3.8)$ & $2.8(2.2-4.0) \dagger$ \\
FEV $_{1} /$ FVC & $0.7(0.5-0.8)$ & $0.3(0.2-0.4)^{* *}$ \\
$\mathrm{KCOC}_{1} \%$ pred & $78(61-92)$ & $50(37-56)^{* * * *}$ \\
\hline
\end{tabular}

Data presented as mean \pm SEM or median (IQR) of $n=14$ controls and $n=15$ patients with emphysema. Mann-Whitney test, $\mathrm{p}=0.07,{ }^{*} \mathrm{p}=0.04$, * $\mathrm{p}=0.0028$

$* * * p=0.0002, * * * * p<0.0001$. TLC data were available for 11 controls and 13 patients with emphysema. Smoking history was available for 12 controls and 10 patients with emphysema. One patient with emphysema declined to make lung function data available.

$\mathrm{KCOC}$, transfer coefficient for uptake of $\mathrm{CO}$ of the lung per unit volume, corrected; TLC, total lung capacity.

$(\mathrm{p}=0.0028)$, and transfer coefficient for uptake of $\mathrm{CO}$, corrected (KCOc, $\mathrm{p}<0.0001$ ) than control patients, as expected.

\section{Cells and reagents}

Pharmacological agents were used to manipulate the RA pathway in cells in vitro. ATRA was used to stimulate RA signalling, having strong affinity for all RARs. ${ }^{24}$ For activation of specific RARs, AM580 (RAR- $\alpha$ agonist), ${ }^{25}$ BMS453 (RAR- $\beta$ agonist $^{26}$ and CD1530 (RAR- $\gamma$ agonist) ${ }^{27}$ were used. To inhibit RA signalling, the pan-RAR inverse agonist BMS493, which antagonises RA signalling by competitively stabilising the association of RAR/RXR heterodimers with transcriptional co-repressors, was used. ${ }^{28}$ All retinoids (all-trans retinoic acid, ATRA (Sigma-Aldrich, Poole, UK \# R2625), BMS493 (Sigma-Aldrich, \#B6688), AM580 (Sigma-Aldrich, \#A884), BMS453 (Tocris Bioscience, Bristol, UK \#3409), CD1530 (Tocris Bioscience \#2554)) were protected from photodegradation and stored as stock solution in dimethyl sulfoxide at $-20^{\circ} \mathrm{C}$ for a maximum of 1 month.

A549 cells were purchased from the European Collection of Cell Cultures (Porton Down, UK) and maintained in Dulbecco's modified eagles medium (DMEM) supplemented with glutamine $(2 \mathrm{mM}), 10 \%$ foetal bovine serum (FBS), and penicillin and streptomycin $(100 \mathrm{U} / \mathrm{mL})$. Human lung microvascular endothelial cells (HLMVEC, Lonza, Wokingham, UK \#CC2527) were maintained in EGM2-MV2 media (Lonza \#3202) and used between passages 3 and 8 with no change in morphology or baseline tube-forming capacity. Primary human alveolar type 2 cells (hAT2) were isolated from normal resected lung tissue by partial enzyme digestion using bovine pancreatic trypsin (Sigma-Aldrich T8003) and preferential adherence to plastic, ${ }^{29}$ and cultured in DCCM-1 media (React Scientific, Ayrshire, UK) supplemented with $10 \%$ neonatal calf serum. Cells were washed with HBSS 48 hours after isolation to remove non-adherent cells, and formed a visually confluent monolayer by 3-4 days after isolation. hAT2 were not passaged.

\section{Treatment protocols}

Bovine serum contains retinoids, thus cells were starved in serum-free medium prior to experiments to minimise baseline RA signalling activity prior to treatments. ${ }^{30}$ To determine target gene induction, confluent A549 cells were serum starved for 
24 hours and treated with ATRA $(1 \mu \mathrm{M})$ dissolved in medium for the indicated times, or with BMS493 dissolved in medium at the indicated concentrations for 20 hours, prior to RNA extraction. Confluent HLMVEC were serum starved for 24 hours and treated with ATRA for 4 hours prior to RNA extraction. Incubation times for mRNA induction were chosen to align with the durations of the functional assays. Proliferation was determined in sub-confluent A549 cells by incubation with antibody specific for phospho-serine 10 H3 (Cell Signaling Technology, \#9701), counterstained with DAPI for nuclear staining, and visualised using a wide-field fluorescent microscope. The percentage of mitotic cells relative to total nuclei was calculated with Image J.

\section{Epithelial scratch assay}

Confluent A549 cells or hAT2 were serum starved for 24 or 2 hours respectively, and a linear scratch was generated with a p200 pipette tip. Cells were incubated at $37^{\circ} \mathrm{C}$ with the indicated treatments dissolved media containing $10 \%$ serum. To determine whether serum-derived retinoids interfere with exogenous ATRA, wound healing experiments were conducted using A549 treated with ATRA in media supplemented with charcoal stripped serum, which is depleted of lipophilic molecules which may have biological activity (such as steroids, peptide hormones and retinoids). ${ }^{31}$ Digital images were acquired immediately and at 18 hours after scratch, and the area covered by migrating cells was calculated with ImageJ software and expressed in pixels. ${ }^{32}$

\section{Matrigel-based angiogenesis assay}

Non-toxic retinoid concentrations were determined in HLMVEC with WST-1 reagent (Roche, Mannheim, Germany $\# 05015944001$ ). HLMVEC were incubated at $37^{\circ} \mathrm{C}$ for 4 hours in culture media containing ATRA, AM580, BMS453 or CD1530 at the indicated concentrations prior to incubation with WST-1. The amount of reduced formazan in the supernatants was spectrophotometrically determined at $450 \mathrm{~nm}$ with a plate reader. Only non-toxic concentrations were used for angiogenesis experiments (see online supplementary material). For the angiogenesis assay, HLMVEC were serum starved for 24 hours, trypsinised and seeded at $25500 / \mathrm{cm}^{2}$ onto solidified growth factor-reduced Matrigel (BD Biosciences, Oxford, UK) in angiogenesis $\mu$-slides (Ibidi, Martinsried, Germany \#81506) and incubated at $37^{\circ} \mathrm{C}$ with EGM2-MV2 with all supplements except serum and hydrocortisone, containing ATRA, AM580, BMS453 or CD1530 at the indicated concentrations. After 4 hours, digital images were acquired, and mean total tube length per field of view quantified with ImageJ software. ${ }^{33}$ Data are expressed as mean total tube length normalised to mean of control.

\section{Quantitative real-time PCR}

RNA was extracted directly from cells treated in six-well plates, or from homogenised whole lung tissue (approximately $30 \mathrm{mg}$ ), with RNeasy Mini Kit (Qiagen). Following this, $1 \mu \mathrm{g}$ RNA was reverse transcribed and analysed by quantitative real-time (qRT)-PCR using specific primers (Applied Biosystems, Foster City, California, USA; details provided in the online supplementary material). Individual Taqman-based assays were used for RALDH-1, RALDH-2 and RALDH-3, CYP26A1, CYP26B1 and CYP26C1, RAR- $\alpha$, RAR- $\beta$ and RAR- $\gamma$, RXR- $\alpha$, RXR- $\beta$ and RXR- $\gamma$, cellular retinol binding protein (CRBP)-1 and CRBP-2, CRABP-1 and CRABP-2, lecithin retinol acyltransferase (LRAT), $\beta$ glucuronidase (GUSB) and $\beta-2$ microglobulin
(B2M). All pathway components were expressed in control and emphysematous lung (see online supplementary material). qRT-PCR reactions were performed in triplicate, and the mean used to calculate fold change in expression between control and emphysema samples according to the $\Delta \Delta \mathrm{CT}$ method. ${ }^{34}$ Glyceraldehyde 3 phosphate dehydrogenase (GAPDH), which we previously found to be the most stable reference gene for analysis of A549 cells with qRT-PCR, ${ }^{35}$ was used as the reference gene for A549 gene expression experiments. GUSB was the most stable reference gene for analysis of whole lung tissue with qRT-PCR, ${ }^{35}$ and in preliminary experiments we found the mean of GUSB and B2M to be suitable for qRT-PCR analysis of whole lung tissue and HLMVEC. To demonstrate the presence of RAR transcripts in hAT2 or HLMVEC, custom designed primers were used in non-quantitative end-point PCR reactions (sequences in online supplementary material), and product size confirmed by electrophoresis on 3\% agarose gel.

\section{Western blot}

Total protein was extracted from whole human lung tissue (approximately $30 \mathrm{mg}$ ) in Cell Lysis Buffer (Cell Signaling \#9803) containing protease inhibitors; $20 \mu \mathrm{g}$ protein was loaded into NuPage 4-12\% Bis-Tris gel (Invitrogen, Carlsbad, California, USA) alongside a protein ladder. Following transfer to nitrocellulose membrane, Western blot was performed with commercially available antibodies: anti-CYP26A1 antibody at 1:500 dilution (Sigma-Aldrich C6498), and anti- $\beta$-actin antibody at 1:2000 dilution (Cell Signalling, Beverly, Massachusetts, USA, \#4970), with HRP-conjugated anti-rabbit secondary antibody (Cell Signaling \#7074) at 1:5000 in blocking buffer. Band intensity was quantified with ImageJ software.

\section{Immunofluorescence}

Whole human lung tissue obtained from resections was inflated with low-melt agarose (Sigma-Aldrich A2576), and a Compresstome VF-300 microtome (Precisionary Instruments Inc., San Jose, California, USA) used to generate tissue slices $400 \mu \mathrm{m}$ thick. Following fixation in $4 \%$ paraformaldehyde, whole-mount immunofluorescence was performed using primary antibodies anti-CYP26A1 (1:100, Sigma-Aldrich C6498), anti-RALDH-1 (1:100, Sigma-Aldrich HPA002123), anti-PECAM-1 (1:100, Sigma-Aldrich P8590) or anti-vimentin (1:100, Abcam ab8069) followed by secondary antibodies Alexa Fluor 555 donkey anti-rabbit (1:500, Life Technologies, A31572) and Alexa Fluor 647 donkey anti-mouse A31571) with ProLong Gold Antifade containing DAPI (Life Technologies) as counterstain. Immunofluorescence was visualised using a Zeiss LSM-510 confocal microscope.

\section{Statistical analysis}

Data were analysed with GraphPad Prism V.6.0 (GraphPad Software Inc, San Diego, California, USA). Non-parametric analyses were used throughout: Mann-Whitney test for two groups, and Kruskal-Wallis test followed by Dunn's post-test for multiple groups.

\section{RESULTS \\ RA does not directly modulate human alveolar epithelial type 2 cell wound healing}

Treatment of A549 cells with ATRA $(1 \mu \mathrm{M})$ increased message at 4 and 20 hours for RAR- $\beta$ ( $p<0.05$, figure $1 A$ ), which contains an RA response element in its promoter region. ${ }^{36}$ Accordingly, concentration-dependent reduction in RAR- $\beta$ was demonstrated in A549 cells with the pan-RAR inverse-agonist 
A

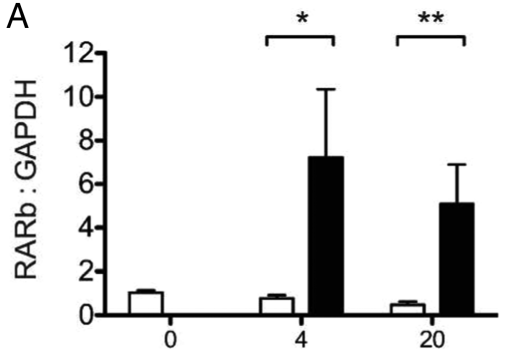

ATRA treatment duration (hours)

C

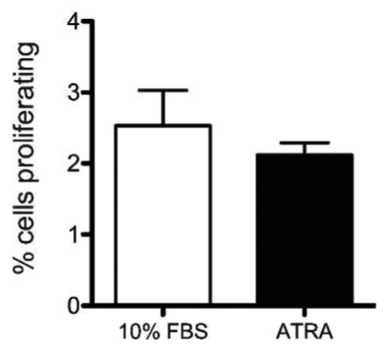

E

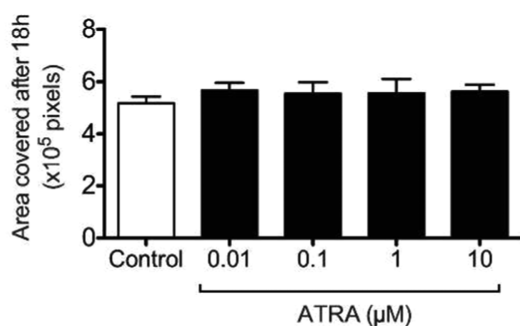

G

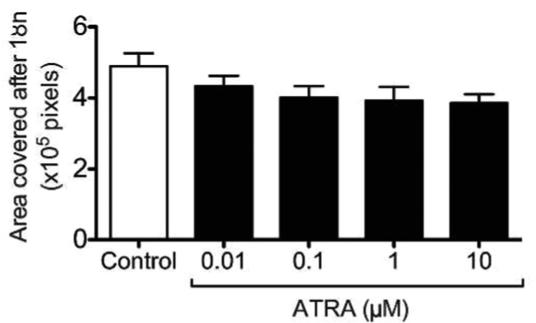

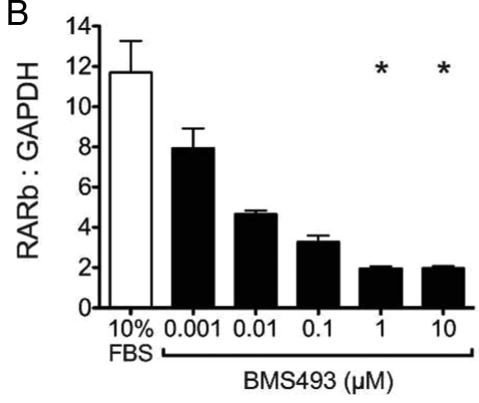

D

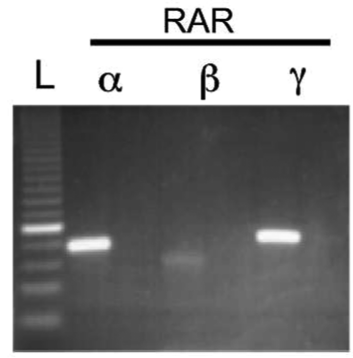

F

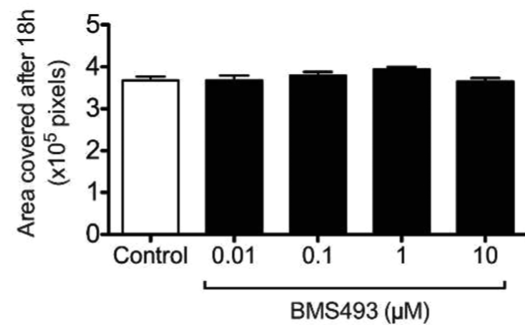

$\mathrm{H}$

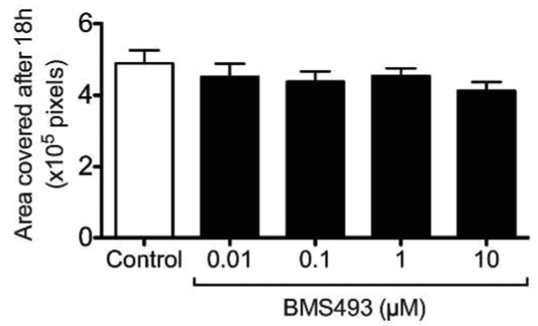

Figure 1 Modulating RA signalling has no effect on A549 or primary human alveolar type 2 cell wound closure. (A) Confluent A549 cells were incubated with DMSO vehicle (empty bars) or with ATRA (1 $\mu \mathrm{M}$, filled bars) for 4 or 20 hours, RNA extracted and quantitative real-time (qRT)-PCR for RAR- $\beta$ performed with expression normalised to GAPDH. Results expressed as mean \pm SEM. $n=4$ per group, ${ }^{*} p<0.05$, ${ }^{* *} p<0.05$ compared with vehicle, Kruskal-Wallis with Dunn's post test. (B) A549 cells were incubated with vehicle or with BMS493 for 20 hours and qRT-PCR for RAR- $\beta$ performed. Results expressed as mean \pm SEM. $n=3$ per group, ${ }^{*} \mathrm{p}<0.05,{ }^{*} \mathrm{p}<0.05$ compared with vehicle, Kruskal-Wallis with Dunn's post test. (C) Sub-confluent A549 cells were incubated with 10\% FBS-supplemented medium either alone or containing ATRA (10 $\mu$ M) for 18 hours, then immunofluorescence performed for phospho-histone $\mathrm{H} 3$ serine 10, and digital images acquired. Nuclei of mitotic cells were calculated in ImageJ as a percentage of total nuclei assessed with DAPI counterstain. $n=2$ per group. (D) RNA was extracted from primary human AT2 cells and non-quantitative RT-PCR performed for RAR- $\alpha$, RAR- $\beta$ and RAR- $\gamma$. Reaction products visualised on agarose gel alongside a 25 bp DNA ladder (L, bright band at $125 \mathrm{bp}$ ). Bands correspond to expected size of amplicons: RAR- $\alpha 97 \mathrm{bp}$, RAR- $\beta 70 \mathrm{bp}, \mathrm{RAR}-\gamma 103$ bp. Confluent A549 cells were scratched with a pipette tip and incubated with 10\% FBS-supplemented medium either alone or containing (E) ATRA or (F) BMS493 for 18 hours Identical experiments were performed with confluent isolated primary human alveolar type 2 (hAT2) cells (G and H), which were scratched and incubated with $10 \%$ FBS alone or containing (G) ATRA or (H) BMS493 for 18 hours. Epithelial closure was quantified using ImageJ. Data presented as mean $\pm S E M, n=a t$ least 5 per group. Kruskal-Wallis test with Dunn's post-test did not detect any significant differences. ATRA, all-trans retinoic acid; FBS, foetal bovine serum; RAR, retinoic acid receptor; GAPDH, glyceraldehyde 3 phosphate dehydrogenase; DAPI, 4',6-diamidino-2-phenylindole.

BMS493, with maximal response at $1 \mu \mathrm{M}(\mathrm{p}<0.05$, figure $1 \mathrm{~B})$. Non-quantitative PCR demonstrated the presence of RAR- $\alpha$, RAR- $\beta$ and RAR- $\gamma$ transcripts in isolated primary human AT2 cells (figure 1D). To examine the role of RA signalling in alveolar epithelial monolayer repair, scratch assays were performed in
A549 and primary hAT2. Neither RA pathway stimulation with ATRA nor inhibition using BMS493 modulated A549 (figure $1 \mathrm{E}, \mathrm{F}$ ) or hAT2 (figure $1 \mathrm{G}, \mathrm{H}$ ) wound closure following a scratch compared with control (medium supplemented with $10 \%$ serum alone). ATRA did not modulate A549 wound 
closure when dissolved in media supplemented with charcoalstripped serum, which is depleted of serum-derived lipids including retinoids (see online supplementary material). Furthermore, treatment of sub-confluent A549 cells with exogenous ATRA $(10 \mu \mathrm{M})$ did not influence proliferation (figure 1C). These data suggest that RA signalling does not directly influence alveolar epithelial repair.

\section{Human lung microvascular cells express retinoic acid receptors and are transcriptionally responsive to RA}

Non-quantitative PCR demonstrated the presence of RAR- $\alpha$, RAR- $\beta$ and RAR- $\gamma$ transcripts in HLMVEC (figure 2A). Using qRT-PCR, concentration-dependent induction of RAR- $\beta$ was demonstrated in HLMVEC with a maximal response at ATRA $10 \mu \mathrm{M}(\mathrm{p}<0.05$, figure $2 \mathrm{~B})$.

\section{RA stimulates angiogenesis in HLMVEC}

ATRA $(10 \mu \mathrm{M})$ significantly increased mean total tube length per field of view in a Matrigel-based angiogenesis assay $(\mathrm{p}<0.05$, figure $2 \mathrm{C}, \mathrm{D})$. This was partially reproduced with AM580 (RAR- $\alpha$ selective agonist), with $\sim 30 \%$ induction at $1 \mathrm{nM}(\mathrm{p}<0.05)$, which diminished with higher concentrations (figure 3A). Toxicity of all retinoids at the concentrations used was excluded with WST-1 (see online supplementary material). Thus, the reduced effect of AM580 at $100 \mathrm{nM}$ and above could be explained by decreased specificity for RAR- $\alpha .{ }^{37}$ No effect of BMS453 (RAR- $\beta$ selective agonist) or CD1530 (RAR- $\gamma$ selective agonist) on HLMVEC angiogenesis was observed (figure $3 \mathrm{~B}, \mathrm{C}$ ).

\section{RA-induced HLMVEC angiogenesis is associated with induction of vascular endothelial growth factor pathway components}

Significant induction of vascular endothelial growth factor A (VEGFA) mRNA was observed following 4 hours of incubation with ATRA $(10 \mu \mathrm{M}, \mathrm{p}<0.05$, figure 4A). A concentrationdependent induction of vascular endothelial growth factor receptor 2 (VEGFR2) was observed, with a maximal response at $10 \mu \mathrm{M}(\mathrm{p}<0.05$, figure $4 \mathrm{C})$. There was no effect on VEGFR1 expression (figure $4 \mathrm{~B}$ ).

\section{RALDH-1 and CYP26A1 protein are present in distinct alveolar cell types}

Whole-mount immunofluorescence on three-dimensional tissue slices derived from normal human lung parenchyma revealed positive immunostaining for the RA-degrading enzyme CYP26A1 in alveolar walls, co-localising with platelet endothelial cell adhesion molecule (PECAM)-1, a specific marker for endothelium (figure 5A-D), in a pattern resembling the microvascular capillary network. Positive immunostaining for the RA-synthesising enzyme RALDH-1 was partially co-localised with the mesenchymal cell marker vimentin (figure 5E-G). RALDH-1 and PECAM-1 exhibited little co-localisation (see online supplementary material). Secondary antibody specificity was demonstrated by absence of signal in sections incubated without primary antibody (see online supplementary material).

\section{CYP26A1 mRNA and protein is increased in emphysematous lung tissue from patients with COPD}

CYP26A1 mRNA expression was significantly higher in emphysematous tissue compared with control lung as shown by qRT-PCR ( $p=0.017$, figure 6A). No other differences in expression were observed (see online supplementary material). By Western blot, relative to band intensity of $\beta$-actin loading control, immunostaining for CYP26A1 protein was significantly greater in emphysematous compared with control lung $(\mathrm{p}=0.016$, figure $6 \mathrm{~B})$, showing an increase similar to mRNA levels.

\section{Reduced diffusion capacity correlates with RA pathway} alterations consistent with diminished local RA availability Significant negative correlations were observed between CYP26A1 and CRABP-1 expressions and KCOc \% predicted (CYP26A1: $p=0.031, r=-0.49$, figure 7A; CRABP-1: $p=0.032$, $\mathrm{r}=-0.49$, figure $7 \mathrm{~B}$, also see online supplementary material). A significant positive correlation was observed between CRBP-2 expression and $\mathrm{KCOc} \%$ predicted $(\mathrm{p}=0.047, \mathrm{r}=0.46$, figure 7C). No correlations were observed between KCOc \% predicted and expression of other RA pathway genes.

\section{DISCUSSION}

The RA signalling pathway controls development, maintenance and regeneration of diverse organ systems, across phylogeny. ${ }^{7}$ In the rodent lung, RA signalling has well characterised roles in regulating alveolar development. ${ }^{9-11}$ In adult animals, exogenous RA can modulate endogenous lung regeneration, ${ }^{13} 14$ and can induce alveolar regeneration in models of experimental emphysema. ${ }^{15-18}$ Regeneration of the alveolar-capillary membrane is critical for restoration of tissue integrity and gas exchange and requires coordinated growth of alveolar epithelium and microvascular endothelium. Alveolar regeneration following injury in animal models of disease involves proliferation and migration of AT2 cells across the basement membrane followed by differentiation into alveolar type 1 (AT1) cells. ${ }^{1}$ Here, we show that exogenous ATRA did not modulate AT2 monolayer scratch wound healing or proliferation, suggesting RA signalling is unlikely to directly control alveolar epithelial repair. In contrast, ATRA stimulated angiogenesis in HLMVEC, an effect partially reproduced by an RAR- $\alpha$ agonist, and ATRA induced mRNA expression of VEGFA and VEGFR2 in HLMVEC. We demonstrate that CYP26A1, which catabolises RA, was localised to the microvascular endothelium in human lung parenchyma, while the RA synthetic enzyme RALDH-1 partially localised to vimentin-positive fibroblasts. CYP26A1 mRNA and protein was increased in emphysematous lung tissue samples from patients with COPD compared with non-emphysematous control lung. These data suggest a mechanism by which endogenous RA signalling may regulate alveolar maintenance and repair in adult human lungs via the pulmonary microvascular endothelium. Furthermore, dysregulated endothelial RA catabolism may contribute to chronic lung disease by curtailing lung repair.

We demonstrate that the human lung epithelial cell line A549 is capable of responding to exogenous RA pathway modulation by altering expression of the RA target gene RAR- $\beta$ (figure 1A, B). Furthermore, primary human AT2 cells express RAR- $\alpha$, RAR- $\beta$ and RAR- $\gamma$ (figure 1C). However, neither RA pathway stimulation with ATRA nor inhibition with BMS493 affected A549 or hAT2 monolayer wound healing in a scratch assay (figure 1D-F, see online supplementary material), and ATRA did not influence proliferation of sub-confluent A549 cells (figure 1C). Together, this suggests that RA signalling does not directly regulate alveolar epithelial repair. This was surprising and contrasts with previous reports of a proliferative role of RA in rat neonatal alveolar epithelial cells, ${ }^{38}$ suggesting the role of RA signalling in juvenile and adult alveolar epithelium may be distinct. Therefore, although alveolar epithelial growth necessarily occurs during RA-induced adult lung regeneration, this may be indirect, mediated by effects of RA on other lung cell types. 


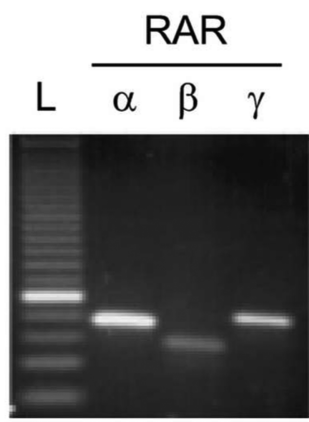

C

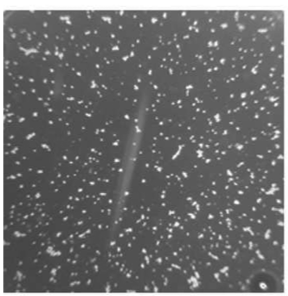

Control
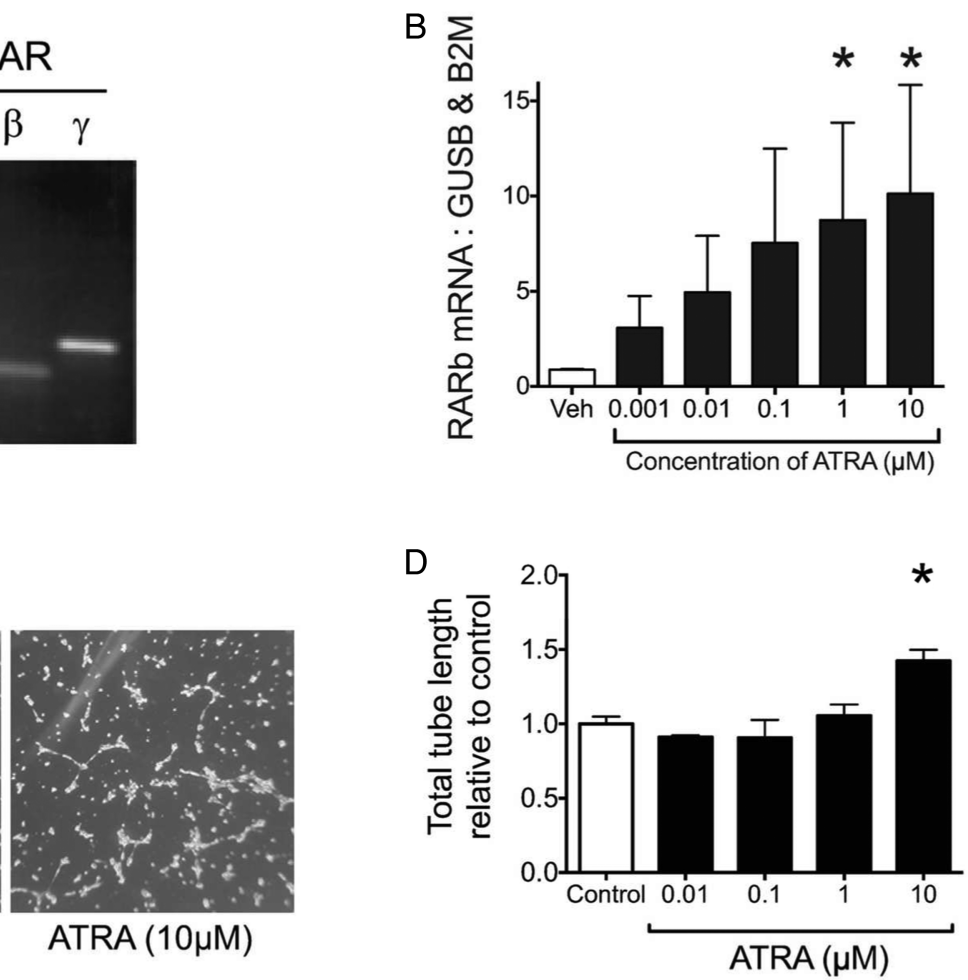

Figure 2 Role of retinoic acid in human lung microvascular endothelial angiogenesis. (A) HLMVEC RNA was extracted and non-quantitative RT-PCR performed for RAR $-\alpha$, RAR- $\beta$ and RAR- $\gamma$. Reaction products visualised on agarose gel alongside a 25 bp DNA ladder (L, bright band at $125 \mathrm{bp}$ ). Bands correspond to expected size of amplicons. (B) HLMVEC were incubated with DMSO vehicle or with ATRA for 4 hours, RNA extracted and quantitative real-time PCR for RAR- $\beta$ performed with expression normalised to mean of GUSB and B2M. Results expressed as mean $\pm S E M$. $n=4$ per group, * $p<0.05$ compared to vehicle, Kruskall-Wallis with Dunn's post test. (C) HLMVEC were seeded onto solidified Matrigel and incubated for 4 hours without (control) or with ATRA. Tube-like structures are visible (arrowheads), representative images shown, original magnification $\times 10$. (D) Quantification of mean total tube length per field of view with ImageJ, expressed relative to control $(\mathrm{Ct})$, as mean $\pm \mathrm{SEM}, \mathrm{n}=4$ per group. ${ }^{*} \mathrm{p}<0.05$ compared with control, Kruskal-Wallis with Dunn's post test. ATRA, all-trans retinoic acid; RAR, retinoic acid receptor; HLMVEC, human lung microvascular endothelial cells; GUSB, $\beta$ glucuronidase; B2M, $\beta$-2 microglobulin.

We have demonstrated that HLMVEC isolated from adult lung express RAR- $\alpha$, RAR- $\beta$ and RAR- $\gamma$ and are ATRA responsive. ATRA stimulated HLMVEC angiogenesis in vitro (figure 2A-D), suggesting that RA-mediated adult lung regeneration was in part mediated by microvascular angiogenesis. This is supported by prior reports: exogenous ATRA stimulated foetal sheep pulmonary artery endothelial cell (PAEC) proliferation and tube branching in vitro. ${ }^{39} \mathrm{RA}$ was sufficient to protect pulmonary vascular development and thus maintain alveolarisation in neonatal mice following anti-angiogenic treatment, ${ }^{40}$ and in a canine model of post-pneumonectomy alveolar regeneration, RA administration preferentially increased microvascular capillary volume and the incidence of double capillaries, thereby enhancing alveolarisation. ${ }^{14}$

We performed exploratory experiments with pharmacological agonists to identify the specific RA receptors involved. Using the angiogenesis assay, we observed a $\sim 30 \%$ induction of tube formation by AM580 $(10 \mathrm{nM})$, a RAR- $\alpha$ agonist (figure $3 \mathrm{~A})$, which may reflect a role for RAR- $\alpha$ in ATRA-induced HLMVEC angiogenesis. The lack of effect by RAR- $\beta$ and RAR- $\gamma$ agonists suggests neither receptor is involved in mediating ATRA-induced angiogenesis (figure 3B, C), however as BMS453 (RAR- $\beta$ agonist) may antagonise RAR- $\alpha$ and RAR- $\gamma$ in vitro, a role for RAR- $\beta$ cannot be excluded. ${ }^{26}$ RAR- $\alpha$ agonists have previously been shown independently to induce angiogenesis, ${ }^{41}$ and lung regeneration. ${ }^{16}$ Notably, mice lacking RAR- $\alpha$ exhibited normal alveoli at 14 days, but failed to continue alveolar development between 14 and 50 days. ${ }^{9}$ This implicates RAR- $\alpha$ in a period of late alveolarisation, in which remodelling of the microvascular network is critical, ${ }^{42}$ supporting a role for RAR- $\alpha$-mediated lung microvascular angiogenesis in postnatal alveolar growth and repair.

In further experiments to identify possible downstream signalling mediators of ATRA-induced HLMVEC angiogenesis, we measured mRNA expression of VEGF pathway members following ATRA incubation, and observed induction of VEGFA and VEGFR2 (figure 4A-C). VEGFA, a pro-angiogenic factor which mediates endothelial cell survival, permeability and angiogenesis through interaction with its receptors VEGFR1 and VEGFR2. It is thus possible that VEGF signalling mediates ATRA-induced HLMVEC angiogenesis. In support of this hypothesis, ATRA-induced foetal sheep PAEC branching was inhibited by a VEGF receptor antagonist, ${ }^{39}$ and RA-induced lung regeneration in mice was associated with increased VEGFR2 expression. ${ }^{43}$

We observed localisation of CYP26A1 protein to a sub-set of alveolar cells in normal human lung parenchyma, co-localising with PECAM-1 staining of the capillary network (figure 5A-D), indicating microvascular endothelial cells produce CYP26A1 protein. CYP26A1, CYP26B1 and CYP26C1 are highly specific, cytosolic cytochrome P450 enzymes that catalyse RA breakdown in RA target cells, and with RALDH-1, RALDH-2 and RALDH-3, regulate local RA availability. ${ }^{7}$ The human CYP26A1 gene contains three and a half conserved RA response elements in its $5^{\prime}$ promoter region and is highly inducible by RA. ${ }^{44}$ From 

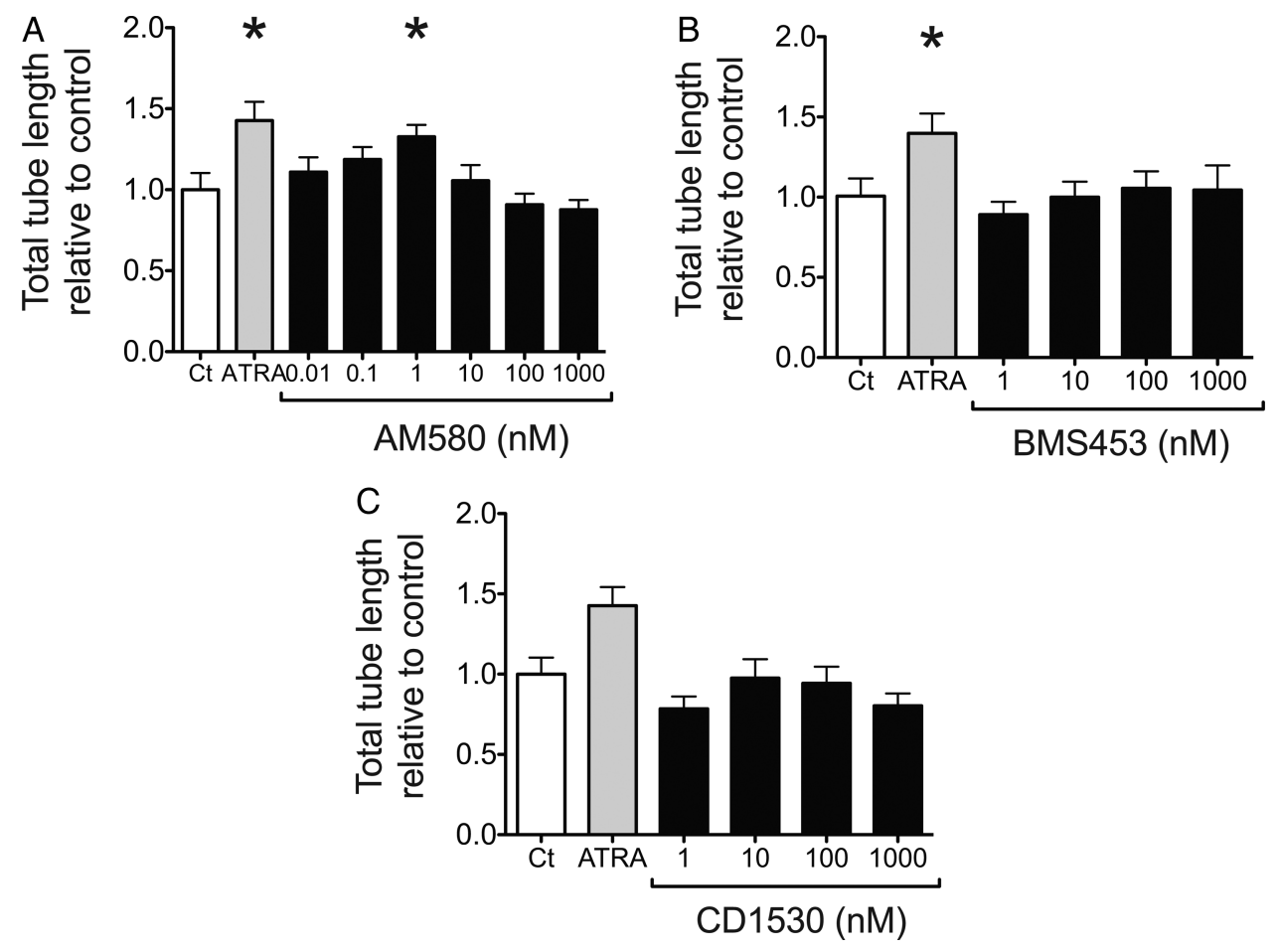

Figure 3 Role of RAR- $\beta$ in HLMVEC angiogenesis. HLMVEC were seeded onto solidified Matrigel and incubated for 4 hours with control media $(C t)$, ATRA $(10 \mu \mathrm{M})$ or with increasing concentrations of (A) AM580, (B) BMS453 or (C) CD1530, and mean total tube length per field of view quantified with ImageJ. Results expressed relative to control $(\mathrm{Ct})$ as mean $\pm \mathrm{SEM}, \mathrm{n}=$ at least 6 per group. * $\mathrm{p}<0.05$ compared with control, Kruskal-Wallis with Dunn's post test. ATRA, all-trans retinoic acid; RAR, retinoic acid receptor; HLMVEC, human lung microvascular endothelial cells.

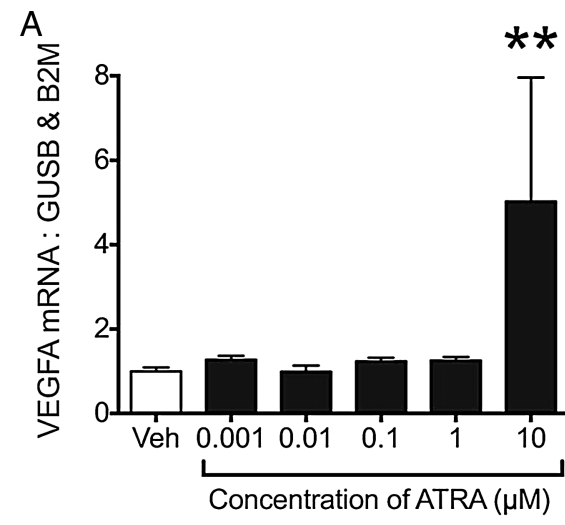

C

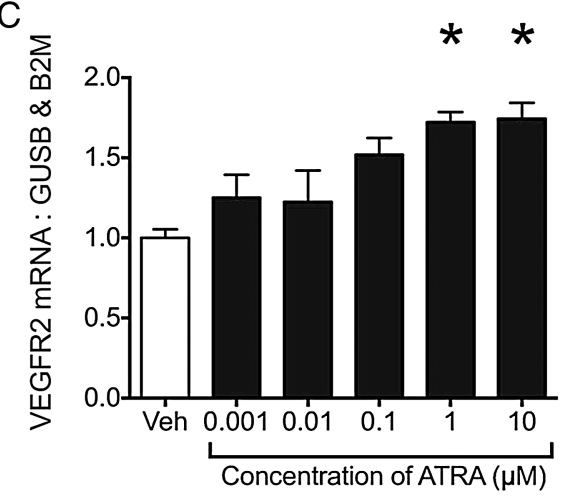

$\mathrm{B}$

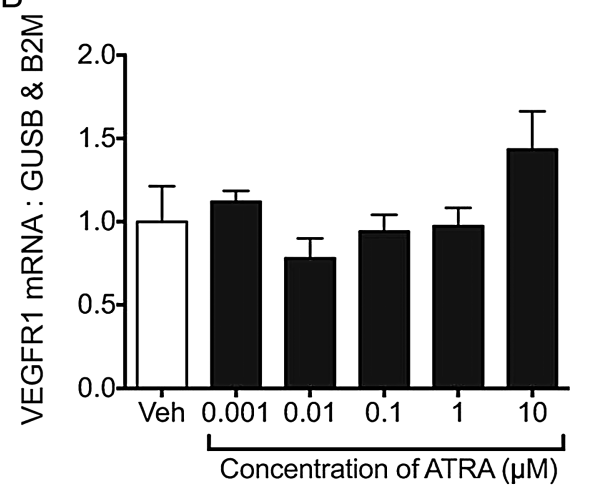




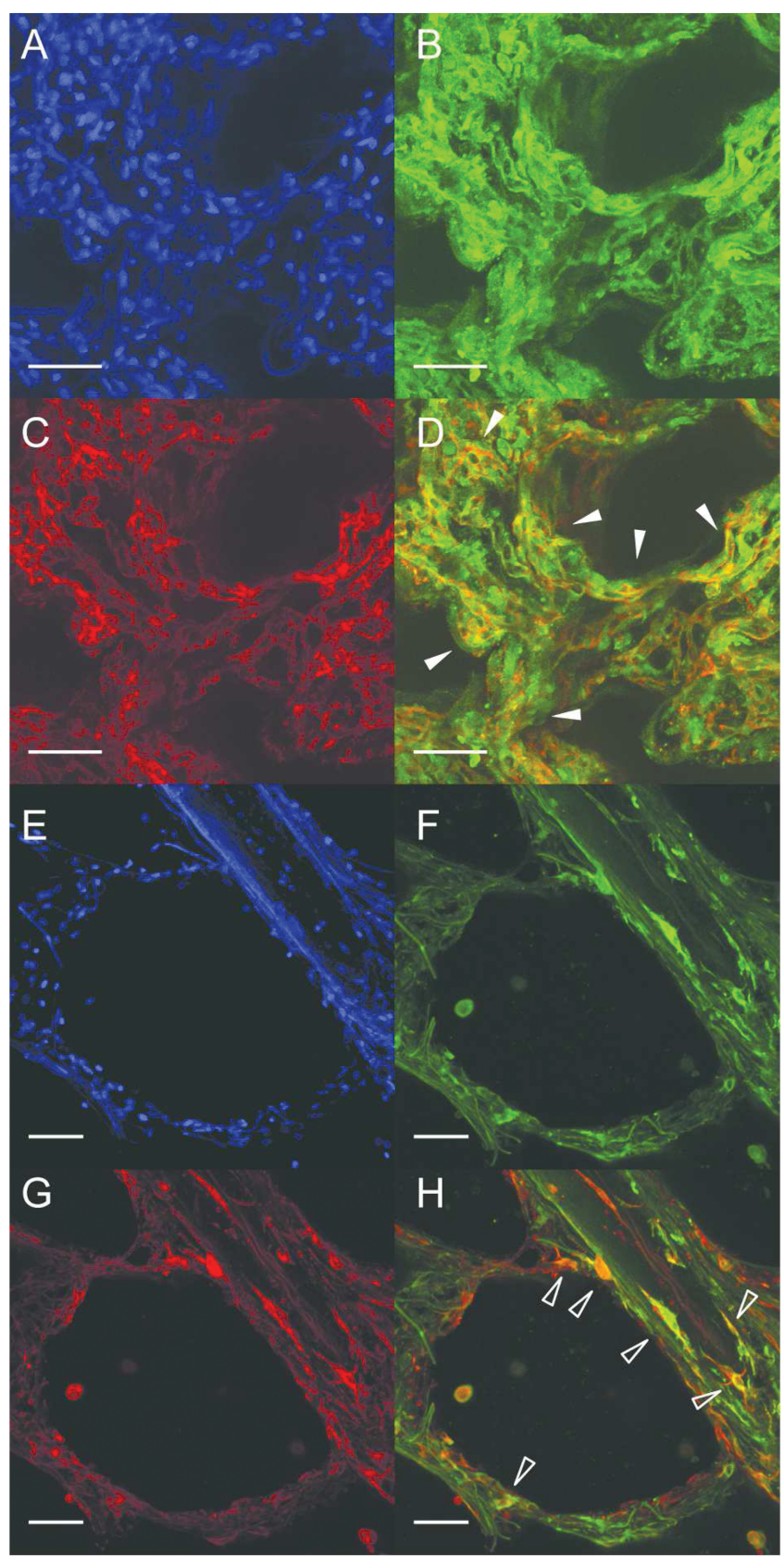

Figure 5 CYP26A1, RALDH-1, PECAM-1 and vimentin localisation in normal human lung parenchyma. Representative maximum intensity projections of Z-stacks through lung slices generated from histologically non-emphysematous adult human lung parenchyma, demonstrating localisation by whole-mount immunofluorescence of CYP26A1, RALDH-1, PECAM-1 and vimentin protein. Co-localisation of CYP26A1 protein ( $B$, green) and PECAM-1 ( , red), to microvascular endothelial cells within the alveolar capillary network (merged in $D$, white arrowheads). Co-localisation of RALDH-1 protein ( $F$, green) and vimentin $(G, r e d)$, to a sub-set of stromal cells with fibroblast-like spindle morphology located near a small airway and within an alveolus (merged in $\mathrm{H}$, empty arrowheads). RALDH-1 was also observed in occasional vimentin-negative cells (white arrowhead in H). DAPI was used as counter-stain ( $A$ and $E$, blue). $20 \times$ original magnification, scale bar $=50 \mu \mathrm{m}$. CYP26A1, cytochrome P450 family 26 subfamily A polypeptide 1; PECAM-1, platelet endothelial cell adhesion molecule 1; RALDH-1, retinaldehyde dehydrogenase 1; DAPI, 4',6-diamidino-2-phenylindole. our observation of CYP26A1 in pulmonary capillary network, we propose the endothelium as a principle target of RA signalling in the adult human lung. RALDH-1 protein partially co-localised with vimentin-positive stromal cells with fibroblastlike spindle morphology located around airways and within alveoli (figure 5E-G). RALDH-1, RALDH-2 and RALDH-3 catalyse the irreversible oxidation of the precursor retinaldehyde (retinal) into biologically active RA. ${ }^{7}$ RALDH-1 did not co-localise with PECAM-1, suggesting the endothelium is not a principle source of endogenous RA in the lung (see online supplementary material). Rather, our data suggest RA synthesis by lung stromal cells and a paracrine mechanism of RA signalling. Previous reports demonstrated RA synthesis and secretion by resident parenchymal lipid body-containing fibroblasts (lipofibroblasts) derived from rat lung. ${ }^{45}$ In mice during postnatal alveolar development, lipofibroblasts localise at the base of emerging septae, suggesting that these cells may drive alveolarcapillary growth. ${ }^{46}$ Our data are consistent with these findings, and correspond to RALDH-1 localisation previously observed in the postnatal mouse lung. ${ }^{47}$ RALDH-1 also localised to a subpopulation of cells that were negative for vimentin, suggesting additional non-endothelial alveolar cell types might produce RA. Together, these data suggest the endothelium as a major target of paracrine RA signalling in human distal lung.

In our patient cohort, increased CYP26A1 mRNA and protein, and thus potentially increased capacity for RA catabolism, correlated with emphysema histology and physiology. CYP26A1 mRNA expression and protein were increased in emphysematous lung tissue from patients with COPD, compared with histologically normal lung tissue from patients with and without obstruction (figure 6A,B). Thus, increased CYP26A1 may be specific to emphysematous changes rather than to COPD generally. Accordingly, post-hoc analysis revealed a significant inverse correlation between CYP26A1 mRNA and KCOc $\%$ predicted $(p=0.031, r=-0.49$, figure 7A). CYP26A1 overexpression in HeLa cells in vitro increased RA degradation, rendering the cells insensitive to $\mathrm{RA}^{48}$ and in vivo, low vitamin A status in mice increased susceptibility to developing emphysema from cigarette smoke exposure. ${ }^{49}$ We also observed a significant inverse correlation between CRABP-1 mRNA expression and KCOc $\%$ predicted $(p=0.032, r=-0.49$, figure 7B). CRABP-1 enhances RA degradation by transporting RA to CYP26s, and overexpression of CRABP-1 in F9 teratocarcinoma cells increased RA catabolism and diminished their sensitivity to RA. ${ }^{50}$ In addition, we found a significant positive correlation between CRBP- 2 and KCOc \% predicted ( $p=0.047$, $\mathrm{r}=-0.49$, figure $7 \mathrm{C}$ ). CRBP-2 transports retinol to LRAT for conversion into retinyl esters, ${ }^{5}{ }^{51}$ therefore, it is possible that decreased CRBP-2 in adult human lung could reduce formation of storage retinoids. Together, these data are consistent with the hypothesis that reduced local RA signalling is associated with the pathogenesis of emphysema.

We did not observe differences in CRABP-2 expression between emphysematous and control lung tissue samples, in contrast to a previous report of reduced CRABP-2 expression in lung fibroblasts from patients with emphysema. ${ }^{23}$ This discrepancy may reflect differences in using whole tissue for analysis compared with primary cells, which may be influenced by isolation protocols or culture conditions, although it is possible that in whole tissue samples, the transcriptional signature of specific cell types is diluted by the presence of other cell types. Because 
A

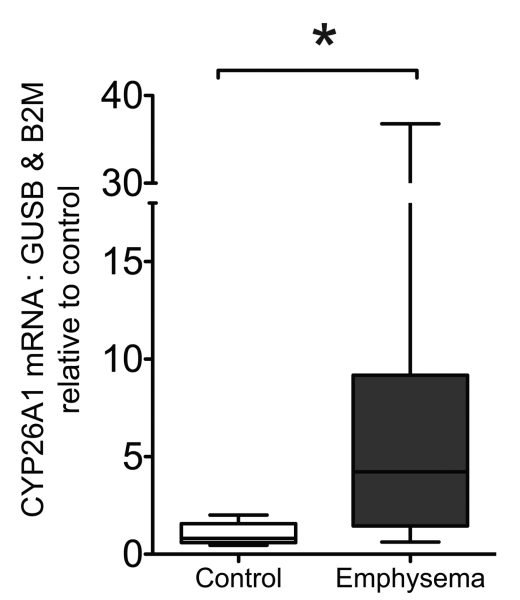

B

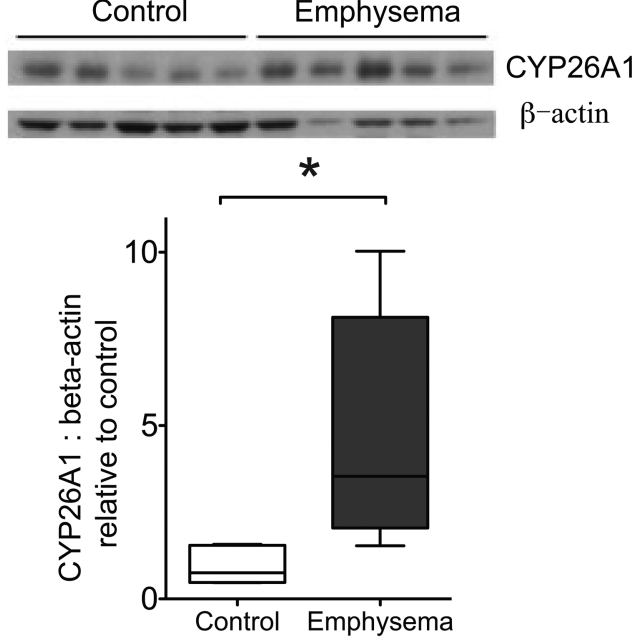

Figure 6 CYP26A1 expression in control and emphysematous lung. (A) CYP26A1 mRNA expression in control ( $n=10)$ and emphysematous ( $n=9$ ) lung. Tissue was processed for RNA extraction, and Taqman-based quantitative real-time PCR performed for CYP26A1 with expression normalised to the mean of GUSB and B2M. Results expressed relative to mean of control group. * $p=0.017$ Mann-Whitney test. (B) CYP26A1 protein was determined in whole lung tissue lysates from a separate cohort of patients ( 5 emphysematous, 5 control) using Western blot with anti-CYP26A1 antibody, with $\beta$-actin as loading control. Graph shows quantification of CYP26A1 band intensity, normalised to $\beta$-actin. Results expressed relative to mean of control group. ${ }^{*} p=0.016$, Mann-Whitney test. Data expressed as box and whisker plots with horizontal line representing the median, and upper and lower bounds of box representing IQR. GUSB, $\beta$ glucuronidase; B2M, $\beta-2$ microglobulin; CYP26A1, cytochrome P450 family 26 subfamily A polypeptide 1 .

the main function of CRABP-2 is to facilitate RA signalling by transporting RA to the nucleus, these prior observations of decreased CRABP-2 expression would also result in reduced RA signalling, ${ }^{23}$ supporting our hypothesis that RA pathway dysregulation contributes to emphysema.

The hypothesis that increased capacity for RA catabolism contributes to emphysema suggests a pharmacokinetic explanation for the negative results of prior studies of exogenous RA in patients with COPD. ${ }^{52} 53$ Synthetic retinoids that are not susceptible to CYP26A1-mediated degradation thus may be more useful in this group of patients. Our finding that an RAR- $\alpha$ agonist partially reproduced ATRA-induced HLMVEC angiogenesis in vitro, together with prior reports that RAR- $\alpha$ agonists can induce lung regeneration in mice, ${ }^{16}$ suggests RAR- $\alpha$ may be a novel therapeutic target for patients with alveolar insufficiency.

Our study has limitations. Pharmacological agonists are not completely selective, the in vitro antagonism of RAR- $\alpha$ and RAR- $\gamma$ by BMS453 being an example. ${ }^{26}$ To define further a role for specific RARs in HLMVEC angiogenesis, molecular disruption of RAR- $\alpha$, RAR- $\beta$ or RAR- $\gamma$, such as with siRNA-mediated knockdown or overexpression of dominant negative mutants, would be required. Similarly, to delineate a role for VEGF signalling, it would be necessary to demonstrate VEGFA or VEGFR2 protein induction by ATRA, and test if VEGF pathway inhibitors (such as the VEGFR2 inhibitor SU1498), or molecular disruption of VEGF pathway components, could interfere with ATRA-induced HLMVEC angiogenesis. Unbiased transcriptional profiling of HLMVEC following ATRA treatment may help reveal other downstream signalling pathways involved. Elucidating the mechanisms of ATRA-induced endothelial repair would help towards developing specific therapies that avoid offtarget effects of modulating RA signalling, which has pleiotropic functions.

The scratch and Matrigel-based angiogenesis assays, although established and widely used models of cellular repair, ${ }^{32} 33$ cannot fully recapitulate the complex molecular events that occur during lung regeneration in vivo. As animal models often inadequately represent human physiology, complex human models of lung repair are needed. Recent progress with human organoid and lung-on-a-chip technology may offer exciting avenues for further testing the hypotheses outlined in our study. ${ }^{54}$ A multicellular assay such as co-culture of HLMVEC with lung fibroblasts may help to determine whether fibroblastderived ATRA can induce HLMVEC angiogenesis, and further addition of hAT2 could test a role for indirect effects of RA on hAT2 repair via other cell types. Precision-cut lung slices are a promising alternative for defining the complex regulation of RA signalling between distinct alveolar cell types. ${ }^{56}$ Using immunofluorescence, we localised CYP26A1 and RALDH-1 to distinct alveolar populations, microvascular endothelium and fibroblasts respectively, suggesting a paracrine mechanism of RA signalling in human distal lung. This is strengthened by the lack of RALDH-1 expression in endothelium. However, we cannot exclude that endothelial cells express other RALDH subtypes (RALDH-2 or RALDH-3). Analysis of CYP26A1 levels in lung microvasculature of patients with emphysema would help to clarify whether endothelial RA catabolic capacity is specifically increased in emphysema. Additional studies of whether HLMVEC from patients with emphysema have altered capacity to respond to exogenous ATRA would provide a further test of our hypothesis.

In summary, we propose that RA is a key repair factor in the human alveolus (summarised in figure 8). Activation of RA signalling in microvascular endothelium by either endogenous RA or an exogenous retinoid stimulates angiogenesis, promoting alveolar regeneration (figure 8A). Conversely, degradation of endogenous RA by increased CYP26A1 impairs endothelial cell repair and may contribute to chronic lung disease (figure $8 \mathrm{~B}$ ). Together, these data contribute to our understanding of how a single essential fat-soluble nutrient, vitamin A, can directly modulate human lung responses in health and disease with potentially important clinical implications. The global variation in the prevalence of COPD is not fully explained by age, 

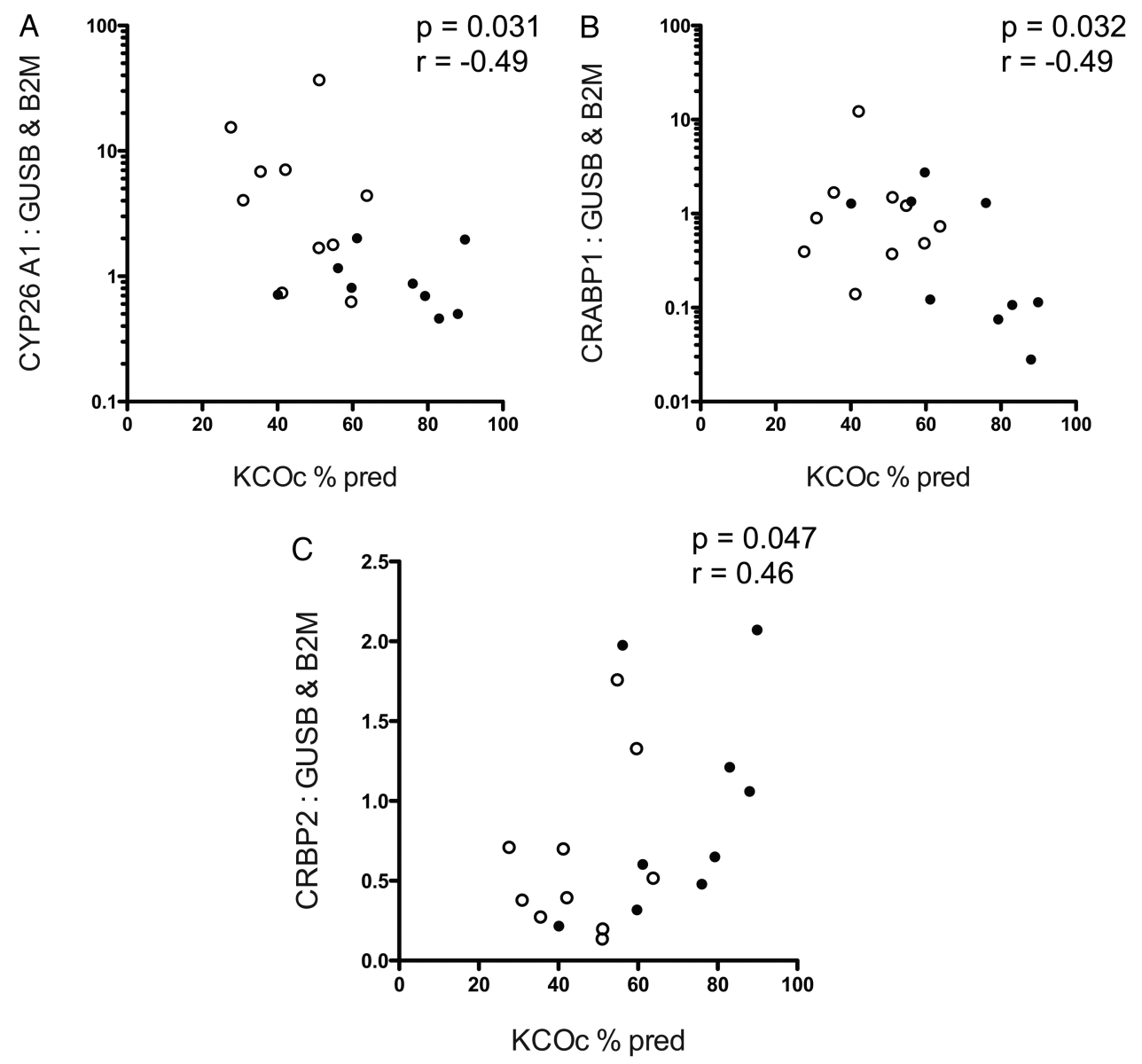

Figure 7 Correlations between CYP26A1, cellular retinoic acid binding protein 1, and cellular retinol binding protein 2 expression and transfer factor (KCOc \% predicted) in COPD. Post-hoc statistical correlation of (A) CYP26A1, B) CRABP1 and C) CRBP2 mRNA expression normalised to mean of GUSB and B2M, with transfer coefficient for CO uptake (KCOC \% predicted). For (A and B), Y-axes are log 10 scale for ease of display. Spearman's correlation, $r=S$ pearman's coefficient. $n=19$, white circles=emphysema, filled circles=control. Abbreviations: GUSB, $\beta$-glucuronidase; B2M, $\beta-2$ microglobulin; CYP26A1, cytochrome P450 family 26 subfamily A polypeptide 1; CRABP1, cellular retinoic acid binding protein 1; CRBP2, cellular retinol binding protein 2 .

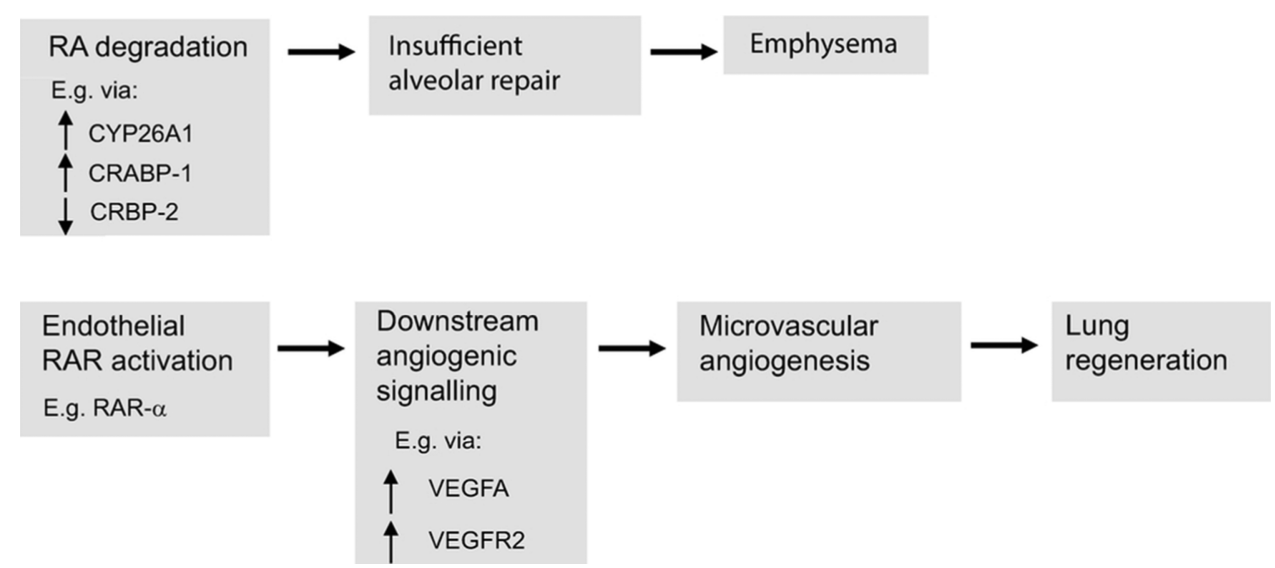

Figure 8 Proposed model of role of RA signalling in emphysema and adult human lung regeneration. In this model, increased RA degradation, for example, through the CRABP-1-CYP26A1 axis, or decreased CRBP-2, contributes to decreased RA levels and a consequent deficiency in RA-mediated endothelial repair, which has a role in the pathogenesis of emphysema. In conditions of RA sufficiency or after exogenous RA administration, RA can stimulate microvascular angiogenesis, for example, through RAR- $\alpha$ activation, mediated by downstream pro-angiogenic signalling such as the VEGF pathway, thus promoting alveolar regeneration. CRABP-1, cellular retinoic acid binding protein 1; CRBP-2, cytoplasmic retinol binding protein 2; CYP26A1, cytochrome P450 subfamily 26 A1; RAR, retinoic acid receptor; VEGFA, vascular endothelial growth factor A; VEGFR2, vascular endothelial growth factor receptor 2. 
cigarette smoking and biomass smoke exposure, and other factors are therefore likely to be important. ${ }^{57}$ Vitamin A deficiency and subclinical deficiency are associated with poverty and are prevalent in the developing world. We suggest targeted intervention studies examining lung health in these populations might be informative.

Contributors JPNB undertook acquisition, analysis and interpretation of data, and manuscript writing. JA undertook acquisition, analysis and interpretation of data for figure 5. MAM undertook acquisition and categorisation of lung tissue samples and provided images of tissue sections for online supplementary material. CHD, MJG, UG and $\mathrm{MH}$ contributed to the study design. All authors contributed to manuscript revision and final approval. All authors agree to be accountable for all aspects of the work in ensuring that questions related to the accuracy or integrity of any part of the work are appropriately investigated and resolved.

Funding This project was funded and supported by the NIHR Respiratory Biomedical Research Unit at the Royal Brompton and Harefield NHS Foundation Trust and Imperial College London.

Competing interests None declared.

Provenance and peer review Not commissioned; externally peer reviewed.

\section{REFERENCES}

1 Kotton DN, Morrisey EE. Lung regeneration: mechanisms, applications and emerging stem cell populations. Nat Med 2014;20:822-32.

2 Butler JP, Loring SH, Patz $\mathrm{S}$, et al. Evidence for adult lung growth in humans. N Engl J Med 2012;367:244-7.

3 Tuder RM, Yoshida T, Arap W, et al. State of the art. Cellular and molecular mechanisms of alveolar destruction in emphysema: an evolutionary perspective. Proc Am Thorac Soc 2006:3:503-10.

4 Warburton D, Tefft D, Mailleux A, et al. Do lung remodeling, repair, and regeneration recapitulate respiratory ontogeny? Am J Respir Crit Care Med 2001;164(Pt 2):S59-62.

5 Duester $\mathrm{G}$. Retinoic acid synthesis and signaling during early organogenesis. Cell 2008;134:921-31.

6 Mark M, Ghyselinck NB, Chambon P. Function of retinoid nuclear receptors: lessons from genetic and pharmacological dissections of the retinoic acid signaling pathway during mouse embryogenesis. Annu Rev Pharmacol Toxicol 2006;46: 451-80.

7 Cunningham TJ, Duester G. Mechanisms of retinoic acid signalling and its roles in organ and limb development. Nat Rev Mol Cell Biol 2015;16:110-23.

8 Chen F, Cao Y, Qian J, et al. A retinoic acid-dependent network in the foregut controls formation of the mouse lung primordium. J Clin Invest 2010;120:2040-8.

9 Massaro GD, Massaro D, Chambon P. Retinoic acid receptor-alpha regulates pulmonary alveolus formation in mice after, but not during, perinatal period. Am J Physiol Lung Cell Mol Physiol 2003:284:L431-3.

10 Massaro GD, Massaro D, Chan WY, et al. Retinoic acid receptor-beta: an endogenous inhibitor of the perinatal formation of pulmonary alveoli. Physiol Genomics 2000;4:51-7.

11 McGowan S, Jackson SK, Jenkins-Moore M, et al. Mice bearing deletions of retinoic acid receptors demonstrate reduced lung elastin and alveolar numbers. Am J Respir Cell Mol Biol 2000;23:162-7.

12 McGowan SE, Holmes AJ, Smith J. Retinoic acid reverses the airway hyperresponsiveness but not the parenchymal defect that is associated with vitamin A deficiency. Am J Physiol Lung Cell Mol Physiol 2004;286:L437-44.

13 Kaza AK, Kron IL, Kern JA, et al. Retinoic acid enhances lung growth after pneumonectomy. Ann Thorac Surg 2001;71:1645-50.

14 Ravikumar P, Dane DM, McDonough P, et al. Long-term post-pneumonectomy pulmonary adaptation following all-trans-retinoic acid supplementation. J Appl Physiol 2011;110:764-73

15 Hind $M$, Maden M. Retinoic acid induces alveolar regeneration in the adult mouse lung. Eur Respir J 2004:23:20-7.

16 Maden M. Retinoids have differing efficacies on alveolar regeneration in a dexamethasone-treated mouse. Am J Respir Cell Mol Biol 2006;35:260-7.

17 Belloni PN, Garvin L, Mao CP, et al. Effects of all-trans-retinoic acid in promoting alveolar repair. Chest 2000;117(Suppl 1):235S-41S.

18 Massaro GD, Massaro D. Retinoic acid treatment abrogates elastase-induced pulmonary emphysema in rats. Nat Med 1997:3:675-7.

19 Checkley W, West KP Jr, Wise RA, et al. Maternal vitamin A supplementation and lung function in offspring. N Engl J Med 2010;362:1784-94.

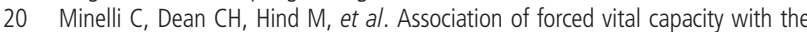
developmental gene NCOR2. PLOS ONE 2016;11:e0147388

21 Schunemann HJ, Grant BJ, Freudenheim JL, et al. The relation of serum levels of antioxidant vitamins $C$ and $E$, retinol and carotenoids with pulmonary function in the general population. Am J Respir Crit Care Med 2001;163:1246-55.
22 Morabia A, Menkes MJ, Comstock GW, et al. Serum retinol and airway obstruction. Am J Epidemiol 1990;132:77-82.

23 Plantier L, Rochette-Egly C, Goven D, et al. Dysregulation of elastin expression by fibroblasts in pulmonary emphysema: role of cellular retinoic acid binding protein 2 . Thorax 2008;63:1012-17.

24 Germain P, Chambon P, Eichele G, et al. International Union of Pharmacology. LX Retinoic acid receptors. Pharmacol Rev 2006;58:712-25.

25 Delescluse C, Cavey MT, Martin B, et al. Selective high affinity retinoic acid receptor alpha or beta-gamma ligands. Mol Pharmacol 1991;40:556-62.

26 Chen JY, Penco S, Ostrowski J, et al. RAR-specific agonist/antagonists which dissociate transactivation and AP1 transrepression inhibit anchorage-independent cell proliferation. EMBO J 1995; 14:1187-97.

27 Bernard BA, Bernardon JM, Delescluse C, et al. Identification of synthetic retinoids with selectivity for human nuclear retinoic acid receptor gamma. Biochem Biophys Res Commun 1992;186:977-83.

28 Germain P, Gaudon C, Pogenberg V, et al. Differential action on coregulator interaction defines inverse retinoid agonists and neutral antagonists. Chem Biol 2009;16:479-89.

29 Witherden IR, Tetley TD. Isolation and culture of human alveolar type II pneumocytes. Methods Mol Med 2001;56:137-46.

30 Van Merris V, Meyer $E$, de Wasch $\mathrm{K}$, et al. Simple quantification of endogenous retinoids in bovine serum by high-performance liquid chromatography-diode-array detection. Analytica Chimica Acta 2002;468:237-44.

31 Cao Z, West C, Norton-Wenzel CS, et al. Effects of resin or charcoal treatment on fetal bovine serum and bovine calf serum. Endocr Res 2009;34:101-8.

32 Liang CC, Park AY, Guan JL. In vitro scratch assay: a convenient and inexpensive method for analysis of cell migration in vitro. Nat Protoc 2007;2:329-33.

33 Arnaoutova I, Kleinman HK. In vitro angiogenesis: endothelial cell tube formation on gelled basement membrane extract. Nat Protoc 2010;5:628-35.

34 Livak KJ, Schmittgen TD. Analysis of relative gene expression data using real-time quantitative PCR and the 2(-Delta Delta C(T)) method. Methods 2001;25:402-8.

35 Pinhu L, Park JE, Yao W, et al. Reference gene selection for real-time polymerase chain reaction in human lung cells subjected to cyclic mechanical strain. Respirology 2008;13:990-9.

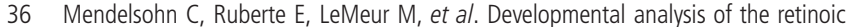
acid-inducible RAR-beta 2 promoter in transgenic animals. Development 1991;113:723-34.

37 Martin B, Bernardon JM, Cavey MT, et al. Selective synthetic ligands for human nuclear retinoic acid receptors. Skin Pharmacol 1992;5:57-65.

38 Baybutt RC, Smith BW, Donskaya EV, et al. The proliferative effects of retinoic acid on primary cultures of adult rat type II pneumocytes depend upon cell density. In Vitro Cell Dev Biol Anim 2010;46:20-7.

39 Yun EJ, Lorizio W, Seedorf G, et al. VEGF and endothelium-derived retinoic acid regulate lung vascular and alveolar development. Am J Physiol Lung Cell Mol Physiol 2016;310:L287-98

40 Cho SJ, George CL, Snyder JM, et al. Retinoic acid and erythropoietin maintain alveolar development in mice treated with an angiogenesis inhibitor. Am J Respir Cell Mol Biol 2005:33:622-8.

41 Saito A, Sugawara A, Uruno A, et al. All-trans retinoic acid induces in vitro angiogenesis via retinoic acid receptor: possible involvement of paracrine effects of endogenous vascular endothelial growth factor signaling. Endocrinology 2007:148:1412-23.

42 Schittny JC, Mund SI, Stampanoni M. Evidence and structural mechanism for late lung alveolarization. Am J Physiol Lung Cell Mol Physiol 2008;294:L246-54.

43 Clerch LB, Baras AS, Massaro GD, et al. DNA microarray analysis of neonatal mouse lung connects regulation of KDR with dexamethasone-induced inhibition of alveolar formation. Am J Physiol Lung Cell Mol Physiol 2004:286:L411-19.

44 Zhang $Y$, Zolfaghari R, Ross AC. Multiple retinoic acid response elements cooperate to enhance the inducibility of CYP26A1 gene expression in liver. Gene 2010;464:32-43.

45 Dirami G, Massaro GD, Clerch LB, et al. Lung retinol storing cells synthesize and secrete retinoic acid, an inducer of alveolus formation. Am J Physiol Lung Cell Mol Physiol 2004;286:L249-56.

46 McGowan SE, Torday JS. The pulmonary lipofibroblast (lipid interstitial cell) and its contributions to alveolar development. Annu Rev Physiol 1997;59:43-62.

47 Hind M, Corcoran J, Maden M. Alveolar proliferation, retinoid synthesizing enzymes, and endogenous retinoids in the postnatal mouse lung. Different roles for Aldh-1 and Raldh-2. Am J Respir Cell Mol Biol 2002:26:67-73.

48 Fujii $\mathrm{H}$, Sato T, Kaneko $\mathrm{S}$, et al. Metabolic inactivation of retinoic acid by a novel P450 differentially expressed in developing mouse embryos. EMBO J 1997; 16:4163-73.

49 van Eij S, Mortaz E, Versluis C, et al. A low vitamin A status increases the susceptibility to cigarette smoke-induced lung emphysema in C57BL/6J mice. J Physiol Pharmacol 2011;62:175-82.

50 Boylan JF, Gudas LJ. The level of CRABP-I expression influences the amounts and types of all-trans-retinoic acid metabolites in $\mathrm{F9}$ teratocarcinoma stem cells. J Biol Chem 1992;267:21486-91. 
51 Wongsiriroj N, Piantedosi R, Palczewski K, et al. The molecular basis of retinoid absorption: a genetic dissection. J Biol Chem 2008;283:13510-19.

52 Mao JT, Goldin JG, Dermand J, et al. A pilot study of all-trans-retinoic acid for the treatment of human emphysema. Am J Respir Crit Care Med 2002;165:718-23.

53 Roth MD, Connett JE, D'Armiento JM, et al. Feasibility of retinoids for the treatment of emphysema study. Chest 2006;130:1334-45.

54 Dye BR, Hill DR, Ferguson MA, et al. In vitro generation of human pluripotent stem cell derived lung organoids. elife 2015;4. http://dx.doi.org/10.7554/eLife.05098
55 Benam KH, Villenave R, Lucchesi $\mathrm{C}$, et al. Small airway-on-a-chip enables analysis of human lung inflammation and drug responses in vitro. Nat Methods 2016;13:151-7.

56 Uhl FE, Vierkotten S, Wagner DE, et al. Preclinical validation and imaging of Wnt-induced repair in human 3D lung tissue cultures. Eur Respir J 2015:46:1150-66.

57 Buist AS, McBurnie MA, Vollmer WM, et al. International variation in the prevalence of COPD (the BOLD Study): a population-based prevalence study. Lancet 2007;370:741-50. 